\title{
Three Cases of Schizoaffective Disorder: Different Pharmacological Interventions
}

\section{Felix-Martin Werner}

Higher Vocational School of Elderly Care and Occupational Therapy, Euro Academy Pößneck, Pößneck, Thuringia, 07381, Germany

\begin{abstract}
Schizoaffective disorder is a psychiatric disease with schizophrenic and affective, i.e. depressive, manic or bipolar symptoms. Three cases are presented, while the course of the disease and a different pharmacological treatment are described. The first patient suffers from a recurrent form with bipolar symptoms. The antipsychotic treatment was switched from haloperidol to clozapine with a superior antipsychotic effect and the two moodstabilzing drugs lithium and carbamazepine. The second patient suffers from recurrent schizomanic symptoms and finally the patient is administered the second-generation antipsychotic drug olanzapine, which reduces negative schizophrenic symptoms. The third patient shows recurrent schizomanic symptoms as well. The antipsychotic treatment was switched to quetiapine with a high affinity for the 5-HT2A receptor. The mechanism of action and the adverse effects of the prescribed drugs are pointed out. The patients remained stable, because they adhere to the pharmacological treatment and because they are socially integrated.
\end{abstract}

Keywords: Carbamazepine; Clozapine; Haloperidol; Lithium; Olanzapine; Quetiapine; Schizoaffective disorder; Ziprasidone

\section{Introduction}

Whereas schizophrenia, a chronic disabling psychiatric disease has a prevalence of $1 \%$ in the population, schizoaffective disorder has a prevalance of $0.5 \%$ [1]. In patients suffering schizoaffective disorder, schizophrenic symptoms are combined with affective, i.e. depressive, manic or bipolar symptoms. Schizophrenic patients show positive schizophrenic (hallucinations, paranoia and delusions), negative schizophrenic (social withdrawal, mutism) and cognitive symptoms. Schizophrenic symptoms mostly become manifest as an acute psychosis. The brain regions involved in schizophrenic symptoms are the prefrontal cortex, hippocampus and the ventral tegmental area. In these brain regions, dopamine and serotonin hyperactivity via $\mathrm{D}_{2}$ and $5-\mathrm{HT}_{2 \mathrm{~A}}$ receptors can be found, and a dysfunction of two presynaptic inhibitory neurotransmitters, namely of GABA via $\mathrm{GABA}_{\mathrm{A}}$ receptors and of glutamate via NMDA (N-methyl-D-aspartate) receptors can be found. Some susceptibility genes of schizophrenia have been discovered [2]. The brain regions involved in affective symptoms are the hippocampus and the brainstem. In depressive symptoms, hypoactivity of monoamines, i.e. of serotonin, noradrenaline and dopamine can be found. In manic symptoms, hyperactivity of dopamine and serotonin in the hippocampus can be found [3]. Besides, dysfunction of GABA and glutamate is combined with these neurotransmitter alterations. $30 \%$ of the schizophrenic patients experienced traumata [4]. Schizoaffective disorder is currently treated by second-generation antipsychotic drugs, such as risperidone, olanzapine, quetiapine, clozapine and aripiprazole. In some cases, mood-stabilizing drugs such as lithium, carbamazepine and valproate are administered additionally [5]. There are different outcomes of schizoaffective disorder, a psychosis with a total remission, a recurrent psychosis with a residual condition and a recurrent psychosis with a deficiency condition [6].

\section{Case Report 1}

The first case report is about a 59-year old woman with a recurrent psychosis and a bipolar form. She suffered psychosis at the age of 24 years for the first time. She had persecution complex, heard voices talking to each other, had sleeping disturbances and had difficulty in performing her work as a kindergarten teacher. She was married at that time and did not succeed to care of her 4-year old daughter. She was treated with an electroconvulsive therapy and with the firstgeneration antipsychotic drug haloperidol, which caused serious movement disturbances. After the treatment in a psychiatric ward, she was administered a long-acting injectable form of haloperidol. Ten years later she divorced from her husband. She still suffered from paranoia, depressive and manic symptoms. She retired after the in-patient treatment. At the age of 43 years, she was readmitted to a psychiatric hospital. The physician decided to change the medication and prescribed $100 \mathrm{mg}$ clozapine, $600 \mathrm{mg}$ carbamazepine and $300 \mathrm{mg}$ lithium acetate. With this medication, the schizophrenic and affective symptoms improved. She remained stable and exerts activities in a selfhelp group.

\section{Case Report 2}

The second case report is about a 68-year old woman with a recurrent schizomanic psychosis. She showed schizomanic psychosis for the first time at the age of 28 years. She suffered paranoia and had accoustic hallucinations. She was treated in a psychiatric ward. After the in-patient treatment, she retired and partly worked as a teacher. However, the psychotic and manic symptoms reoccured and she tried suicide several times. She was treated with $100 \mathrm{mg}$ clozapine, and the schizoamanic symptoms improved. Ten years ago, she was switched from clozapine to the second-generation antipsychotic drug quetiapine (400 mg). With this medication, the residual symptoms improved very much, and she is still active in a self-help group.

*Corresponding author: Werner FM, Medical Doctor, $\mathrm{Dr}$. Med, Research field: neural networks in neurological and psychiatric diseases University of Salamanca, Instituto de Neurociencias de Castilla y León (INCYL), Laboratorio de Neuroanatomía de los Sistemas Peptidérgicos (Lab. 14), c/Pintor Fernando Gallego, 1, 37007-Salamanca, Spain, Tel: +34/923/294400, extn. 1856; Fax: +34/923/29 45 49; E-mail: felixm-werner@versanet.de

Received July 15, 2017; Accepted August 14, 2017; Published August 21, 2017

Citation: Werner FM (2017) Three Cases of Schizoaffective Disorder: Different Pharmacological Interventions. J Cytol Histol 8: 470. doi: 10.4172/21577099.1000470

Copyright: () 2017 Werner FM. This is an open-access article distributed under the terms of the Creative Commons Attribution License, which permits unrestricted use, distribution, and reproduction in any medium, provided the original author and source are credited. 


\section{Case Report 3}

The third case report is about a 42-year old woman with a recurrent schizomanic psychosis. She developed schizomanic symptoms for the first time at the age of 18 years. She had paranoia and had accoustic hallucinations. She then was treated with haloperidol (8 $\mathrm{mg}$ ) and after the in-patient treatment she studied dietitics. Since the schizomanic symptoms reoccured several times, she partially retired. The pharmacological treatment was switched from ziprasidone to olanzapine $(10 \mathrm{mg})$, and the suicide attempts disappeared. She got married at the age of 30 years and had a son. She is still active in a parttime work.

\section{Pharmacological Treatment of Schizoaffective Disorder}

Schizoaffective disorder is currently treated by second-generation antipsychotic drugs, which can be combined with mood-stabilizing drugs such as lithium or carbamazepine or with antidepressant drugs, if the patient has schizophrenic and depressive symptoms. Second-generation antipsychotic drugs are mostly antagonists of the dopaminergic $\mathrm{D}_{2}$ receptor and of the serotonergic $5-\mathrm{HT}_{2 \mathrm{~A}}$ receptor [5]. Mood-stabilizing drugs ameliorate depressive and manic symptoms [7]. Antidepressant drugs, which block the reuptake of monamines, improve depressive symptoms [3].

\section{First Generation Antipsychotic Drugs}

First-generation antipsychotic drugs have an antagonistic effect at the dopaminergic $\mathrm{D}_{2}$ receptor and at other receptors. These drugs treat positive schizophrenic and manic symptoms, however they cause extrapyramidal symptoms to a greater extent and more often than second-generation antipsychotic drugs. They have a weak therapeutic effect on negative schizophrenic symptoms [6].

\section{Haloperidol}

Haloperidol is FGA with a high affinity for the $\mathrm{D}_{2}$ receptor. It improves positive schizophrenic symptoms and manic symptoms, but causes often dystonia, parkinsonism and akathisia. An application as a long-acting injectable form is available [8]. The patient in case report 1 suffered very much from movement disturbances in the legs. The patient in case report also indicated extrapyramidal symptoms.

\section{Second-Generation Antipsychotic Drugs}

Schizoaffective disorder is currently treated by second-generation antipsychotic drugs (SGAs), which are mostly antagonists of the dopaminergic $\mathrm{D}_{2}$ receptor and of the serotonergic $5-\mathrm{HT}_{2 \mathrm{~A}}$ receptor. They treat positive schizophrenic symptoms, reduce negative schizophrenic symptoms and improve manic symptoms. Among the SGAs, olanzapine, quetiapine, ziprasidone and clozapine will be mentioned [5].

\section{Olanzapine}

Olanzapine is a SGA with an antagonism at the $\mathrm{D}_{2}$ and $5-\mathrm{HT}_{2 \mathrm{~A}}$ receptors, while it has a lower affinity for the $\mathrm{D}_{2}$ receptor and $\mathrm{a}$ greater affinity for the $5-\mathrm{HT}_{2 \mathrm{~A}}$ receptor than risperidone. It improves negative schizophrenic symptoms better than risperidone and exerts a good antipsychotic and antimanic effect. It induces extrapyramidal symptoms (EPS) to a lesser extent than risperidone, because its affinity for the $\mathrm{D}_{2}$ receptors is lower than that of risperidone. It causes metabolic and cardiac adverse effects more often than risperidone. It belongs to the prolactin-sparing antipsychotic drugs [9]. The patient in case report 3 has reached a stable form of schizoaffective disorder, since she has been talking olanzapine. She does not suffer from extrapyramidal symptoms.

\section{Quetiapine}

Quetiapine is a SGA with an antagonism at the $\mathrm{D}_{2}$ and $5-\mathrm{HT}_{2 \mathrm{~A}}$ receptors, while it has a lower affinity for the $\mathrm{D}_{2}$ receptor and a greater affinity for the $5-\mathrm{HT}_{2 \mathrm{~A}}$ receptor than olanzapine. It exerts good antipsychotic and antidepressive properties. It seldom causes EPS and is a prolactin-sparing antipsychotic drug. It causes metabolic and cardiac adverse effects like risperidone [10]. The patient in case report 2 was treated with quetiapine, and the psychotic and affective symptoms were improved very much. She suffers from sedation after taking the prescribed antipsychotic drug.

\section{Ziprasidone}

Ziprasidone is a SGA with an antagonism at the $\mathrm{D}_{2}$ and $5-\mathrm{HT}_{2 \mathrm{~A}}$ receptors and an agonism at the $5-\mathrm{HT}_{1 \mathrm{~A}}$ receptor. It exerts good antipsychotic and antidepressive effects. It seldom causes EPS and is a prolactin-sparing antipsychotic drug. It causes metabolic and cardiac adverse effects to a lesser extent than risperidone, olanzapine and quetiapine [11]. The patient in case report 3 indicated that with the medication of ziprasidone she had suicide thoughts which improved, after the treatment with ziprasidone was switched to a pharmacotherapy with olanzapine.

\section{Clozapine}

Clozapine is a SGA with an antagonism at the D3, D4 and 5-HT2A receptors. It exerts a stronger antipsychotic effect than other SGAs and is restricted to treatment-resistant form of psychotic disorders. It seldom causes EPS and does not raise prolactin levels. It causes metabolic and cardiac adverse effects like olanzapine. $3 \%$ of the patients treated by clozapine show neutropenia or agranulocytosis [12]. Clozapine improved very much the paranoid symptoms and accoustic hallucinations in the patient in case report 1 . The white blood cell count was controlled every three weeks. Clozapine also treated the schizomanic symptoms in case report 2 and the suicide thoughts.

\section{Mood-stabilizing drugs}

Mood-stabilizing drugs are administered to patients with schizoaffective disorder, especially if schizophrenic symptoms are combined with alternative depressive and manic symptoms. Here, the mechanism of action of lithium and carbamazepine are described [6].

\section{Lithium}

Lithium has a therapeutic effect on depressive, manic and bipolar symptoms. It inhibits the excitatory effect of dopamine and glutamate and increases the presynaptic inhibitory effect of GABA. One third of the patients treated with lithium have no recurrence of affective symptoms. The cardio- and nephrotoxic adverse effects of lithium have to be considered [13]. Lithium improved the alternating affective symptoms in the patient in case report 1 . The patient suffered from a tremor. The parameters of the heart, the kidneys and the thyroid gland were controlled regularly.

\section{Carbamazepine}

Carbamazepine is an antiepileptic drug, which blocks fastinactivated sodium channels. It does not activate or block neurotransmitter receptors. It is recommended in patients with schizoaffective disorder or in schizophrenic patients with E.E.G. 
abnormalities [14]. In the patient in case report 1, the parameters of the liver were controlled regularly.

\section{Conclusion}

This case report summarizes three cases of schizoaffective disorder. In the first case report, a recurrent form is described with schizophrenic and bipolar symptoms. After a treatment with the FGA haloperidol, the treatment was switched to clozapine with a superior antipsychotic effect and the two mood-stabilizing drugs lithium and carbamazepine. With this medication, the paranoid and affective symptoms improved. The patient remained stable, because she has an insight in the disease and because she is integrated in a self-help group. The case report 2 and 3 describes a recurrent form with schizophrenic and manic symptoms. In the second case report, the schizophrenic and manic symptoms improved, after the treatment was switched from clozapine to quetiapine with a high affinity for the $5-\mathrm{HT}_{2 \mathrm{~A}}$ receptor. The patient remained stable and is active in a self-help group. In the third case report, the patient remained stable, since she was switched from ziprasidone to olanzapine. Olanzapine is an SGA with a higher affinity for the $5-\mathrm{HT}_{2 \mathrm{~A}}$ receptor than risperidone and which reduces negative schizophrenic symptoms better than other SGAs. The patient is married and is working in a part-time work.

\section{Conflicts of Interest}

Authors declared no conflict of interest.

\section{References}

1. Klosterkötter J (2008) Indicated prevention of schizophrenia. Dtsch Arztebl In 105: 532-539.

2. Werner F-M, Coveñas R (2013) Classical neurotransmitters and neuropeptides involved in schizophrenia: How to choose the appropriate antipsychotic drug? Curr Drug Ther 8: 132-43.
3. Werner F-M, Coveñas R (2010) Classical neurotransmitters and neuropeptides involved in major depression: a review. Int J Neurosci 120: 455-470.

4. Haller SC, Padmanabhan JL, Lizano P, Torous J, Keshavan M (2014) Recent advances in understanding schizophrenia. F1000 Prime Reports 6: 57.

5. Werner F-M, Coveñas R (2014) Safety of antipsychotic drugs: focus on therapeutic and adverse effects. Exp Opin Drug Saf 13: 1031-1042.

6. Werner F-M, Coveñas R (2016) Classical Neurotransmitters and Neuropeptides Involved in Schizoaffective Disorder: Focus On Prophylactic Medication. BenthamScience Publishers Sharjah.

7. Rajina $P$ (2008) Antiepileptic drugs as mood stabilizers: what did we learn from the epileptology? Ideggyogy Sz 61: 305-316.

8. Khan AY, Salaria S, Ovais M, Ide GD (2016) Depot antipsychotics: Where do we stand? Ann Clin Psychiatry 28: 289-298.

9. Bodén R, Edman G, Reutfors J, Ostenson CG, Osby U (2013) A comparison of cardiovascular risk factors for ten antipsychotic drugs in clinical practice. Neuropsychiatr Dis Treat 9: 371-377.

10. Amr M, Lakhan SE, Sanhan S, Al-Rhaddad D, Hassan M, et al. (2013) Efficacy and tolerability of quetiapine versus haloperidol in first-episode schizophrenia: a randomized clinical trial. Int Arch Med 6: 47.

11. Chue P, Mandel FS, Thierren F (2014) The effect of ziprasidone on metabolic risk factors in subjects with schizophrenia: a 1 year, open-label, prospective study. Curr Med Res Opin 30: 997-1005.

12. Constantine RJ, Andel R, McPherson M, Tandon R (2015) The risks and benefits of switching patients with schizophrenia or schizoaffective disorder from two to one antipsychotic medication: A randomized controlled trial. Schizophr Res 166: 194-200.

13. Malhi GS, Tanious M, Coulston CM, Berk M (2013) Potential mechanisms of action of lithium in bipolar disorder: current understanding. CNS Drugs 27 135-153.

14. Kulkarni J, Filia S, Berk L, Filia K, Dodd S, et al. (2012) Treatment and outcomes of an Australian cohort of outpatients with bipolar I or schizoaffective disorder over twenty-four months: implications for clinical practice. BMC Psychiatry 12: 228 